\title{
Patient experiences and provider perspectives on a hospital-based food pantry: a mixed methods evaluation study
}

\author{
Eva Greenthal ${ }^{1, *}$, Jenny Jia ${ }^{2}$, Ana Poblacion ${ }^{3}$ and Thea James ${ }^{4}$ \\ ${ }^{1}$ Friedman School of Nutrition Science and Policy, Tufts University, Boston 02111 , MA, USA: ${ }^{2}$ Internal Medicine/ \\ Preventive Medicine, Boston Medical Center, One Boston Medical Center Place, Boston 021 18, MA, USA: ${ }^{3}$ Children's

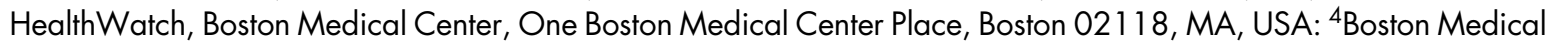 \\ Center, One Boston Medical Center Place, Boston 021 18, MA, USA
}

Submitted 29 December 2018: Final revision received 20 March 2019: Accepted 3 May 2019: First published online 5 September 2019

\begin{abstract}
Objective: The purpose of this evaluation study was to identify strengths and opportunities for improvement in programme functioning and common aspects of patients' experiences at a hospital-based food pantry.

Design: Semi-structured, in-depth interviews with patients and a cross-sectional survey for providers were used. Interview transcripts were coded using both inductive and deductive approaches and assessed for inter-rater reliability. Descriptive statistics were produced from quantitative data.

Setting: An academic urban safety-net hospital in the Northeastern US offering inpatient and outpatient services.

Participants: Thirty patients and 89 providers.

Results: Patients expressed feeling comfortable, trusting the food, high satisfaction with food quality, convenience, and lack of stigma at the hospital-based pantry. Patients mentioned the pantry helped them eat more fruits and vegetables, but expressed concerns about the healthfulness of other foods distributed. Providers believed they should discuss food insecurity (FI) with patients (99\%) and that the pantry improves the health of patients ( $97 \%$ ), but faced barriers to consistently screening for FI and referring patients to the pantry, such as insufficient training on FI (53\%) and time constraints (35\%).

Conclusions: Findings suggest hospital-based food pantries may have several advantages. Hospitals with onsite food pantries must work to eliminate barriers to FI screening and pantry referral. To optimize their impact, such pantries should develop nutritional guidelines for food donations and connect patients with nutrition education resources. Future research should examine health outcomes for patients using hospital-based food pantries.
\end{abstract}

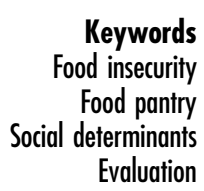

Keywords Food insecurity determinants Evaluation
Redlining, disinvestments, and other structural barriers have created neighbourhoods in the United States that are devoid of opportunities for economic development, impactful employment, and other prerequisites to wealth building $^{(1,2)}$. This history of disenfranchisement has led to socioeconomic disparities, including disparities in access to healthy, affordable food. In 2017, an estimated $11.8 \%$ of American households were food insecure at least some time during the year ${ }^{(3)}$. Food insecurity (FI), defined as lack of access to enough food for an active, healthy life ${ }^{(4)}$ is an economic and social condition linked to numerous negative health outcomes. A 2015 review reported that children living in food insecure households have increased risk of birth defects, anaemia, lower nutrient intakes, cognitive problems, aggression, and anxiety, while adults have increased risk of mental health problems, diabetes, hypertension, and poor sleep outcomes ${ }^{(5)}$, even after controlling for confounding risk factors, such as income and race ${ }^{(6-8)}$.

Many factors contribute to the association between FI and diet-related disease. People with low incomes often lack physical access to affordable healthy food ${ }^{(9)}$; may lack knowledge and skills related to nutrition and food preparation to ensure a healthy $\operatorname{diet}^{(10,11)}$; and have numerous stressors that have been associated with unhealthy eating $^{(12)}$. People in poverty may also have more difficulty adhering to medication regimens ${ }^{(13)}$. 
Trends in food assistance and healthcare demonstrate increasing recognition of the connection between FI and health. Food assistance organizations, such as food pantries and food banks, are increasing distribution of healthier options to their patrons ${ }^{(14-17)}$ and medical practices are screening patients for FI and connecting patients with food assistance resources ${ }^{(18,19)}$. Such efforts are beginning to form the bridge between FI and diet-related diseases, with some health care institutions going even further by operating onsite food pantries.

This study evaluates a medically-tailored food pantry at an academic urban safety-net hospital in the Northeastern US (henceforth referred as 'pantry' and 'hospital,' respectively). The hospital's outpatient clinics routinely screen patients for FI along with other social determinants of health (SDH). Those who are identified as food insecure are eligible to be referred to the pantry. Providers can elect to list chronic diseases on the referral form so that the pantry will tailor the food that that patient receives. Patients with cancer, HIV/ AIDS, hypertension, diabetes, obesity, heart disease, and other chronic conditions often use the pantry. The hospital also houses a teaching kitchen through which patients can attend free cooking classes and learn to make simple, cost-effective recipes that are appropriate for their dietrelated health conditions. Providers sometimes promote the teaching kitchen along with food pantry referrals.

The pantry - which is open from 10.00 to 16.00 hours every weekday - stocks fresh fruits, vegetables, and meats year-round along with non-perishable items such as cereal, pasta, peanut butter, and canned fruits and vegetables. Approximately $90 \%$ of the food is ordered through the local food bank's online ordering system, while $10 \%$ is received through private donations and food drives. At the pantry, patients receive approximately three to four days' worth of food for their entire households up to twice per month. On average, the pantry receives over 1800 patient visits each month.

The pantry has been in operation for almost two decades, and this is its first evaluation study. To our knowledge, this is the first published evaluation of a hospital-based food pantry. This study sets out to identify strengths and opportunities for improvement in programme functioning and common aspects of patients' experiences at the pantry in order to make recommendations for quality improvement and lay the groundwork for an outcome evaluation.

\section{Methods}

In June and July 2018, semi-structured, in-depth interviews were conducted with a convenience sample of hospital patients who use the pantry. Concomitantly, an online survey was administered via Qualtrics (Provo, UT) to hospital healthcare providers. Survey and interview instruments were developed with input from experts and stakeholders. This study was approved by the Tufts Health Sciences IRB.

\section{Data collection}

Flyers inviting patients to contact the researcher by phone or email to schedule in-person interviews were disseminated by volunteers and pantry staff while distributing groceries to pantry users. In order to recruit additional interviewees, the researcher approached patients as they entered or exited the pantry. Eligibility criteria included (i) at least one previous visit to the pantry, and (ii) English proficiency. Each patient was offered a $\$ 10$ gift card to a local grocery chain as an incentive for participation. Interviews were conducted in a private conference room attached to the pantry. The researcher obtained the informed consent of subjects prior to each interview. The interview schedule included questions about demographic characteristics (age, sex, household size and race/ethnicity), food assistance, food security, diet, nutrition education, and perceptions of the pantry (see Supplementary material, Patient Interview Schedule). Food security was assessed using a one-item screener which asked, 'In the past month how often have you felt worried or concerned about having enough food to feed yourself and your family? (Never, Sometimes, Often, or Very Often).'

All providers in the hospital's Internal Medicine, Pediatrics, Women's Health, Family Medicine, and Immigrant and Refugee Health departments, whose email addresses were publicly available, as well as all secondyear and outgoing medical residents receiving emails through their cohorts' listservs, were invited to participate in the survey. Departments were selected based on a high volume of patients referred to the pantry. To promote survey completion, an initial email and two follow-up emails were sent inviting providers to participate in the survey; in-person announcements were made at staff meetings and at academic sessions for residents; a link to the survey was included in some departments' e-newsletters; and providers could enter a drawing for one $\$ 50$ gift card. The survey was completed anonymously. It included a statement obtaining free and informed consent of subjects and 14 multiple choice and short response questions regarding demographic characteristics (age, sex, position, department, and years in practice); experience and perceptions about discussing FI with patients; and experience and perceptions about the pantry (see Supplementary material, Provider Survey). All providers who completed at least $50 \%$ of the survey were included in the sample.

\section{Data analysis}

All interviews were audio-recorded and transcribed. A codebook was developed using both deductive and inductive coding by one researcher and validated by a second. The test for inter-rater reliability revealed 94-100\% agreement on all assigned nodes. Transcripts underwent coding and thematic analysis using NVivo, version 12.1.0.

The provider survey was active for one month. Responses were downloaded from Qualtrics into Microsoft Excel, 
Table 1 Characteristics of patients

\begin{tabular}{|c|c|c|}
\hline Characteristic & $n$ & $\%$ \\
\hline Total & 30 & \\
\hline \multicolumn{3}{|l|}{ Sex } \\
\hline Female & 20 & 67 \\
\hline \multicolumn{3}{|l|}{ Race/Ethnicity } \\
\hline Black & 22 & 73 \\
\hline Hispanic & 5 & 17 \\
\hline Caucasian & 2 & 7 \\
\hline Other & 1 & 3 \\
\hline \multicolumn{3}{|l|}{ Age } \\
\hline Under 50 & 7 & 23 \\
\hline $50-64$ & 16 & 53 \\
\hline $65+$ & 7 & 23 \\
\hline \multicolumn{3}{|l|}{ Children in household? } \\
\hline Yes & 16 & 53 \\
\hline \multicolumn{3}{|l|}{ Household Size } \\
\hline 1 & 10 & 33 \\
\hline 2 & 9 & 30 \\
\hline 3 & 4 & 13 \\
\hline $4+$ & 7 & 23 \\
\hline \multicolumn{3}{|l|}{ Food insecure in the past month? } \\
\hline Yes & 18 & 60 \\
\hline No & 10 & 33 \\
\hline Missing & 2 & 7 \\
\hline \multicolumn{3}{|l|}{ SNAP participant? } \\
\hline Yes & 16 & 53 \\
\hline No & 13 & 43 \\
\hline Missing & 1 & 3 \\
\hline \multicolumn{3}{|l|}{ Use other food pantries? } \\
\hline Yes & 15 & 50 \\
\hline No & 14 & 47 \\
\hline Missing & 1 & 3 \\
\hline Neither SNAP nor other pantries & 7 & 23 \\
\hline \multicolumn{3}{|l|}{ Time using the hospital-based pantry } \\
\hline Less than 1 year & 8 & 27 \\
\hline $1-3$ years & 11 & 37 \\
\hline $4-6$ years & 6 & 20 \\
\hline $7+$ years & 5 & 17 \\
\hline \multicolumn{3}{|c|}{ Frequency of visits to the hospital-based pantry } \\
\hline Every 2 weeks & 13 & 43 \\
\hline Once per month & 11 & 37 \\
\hline Less than once per month & 4 & 13 \\
\hline Missing & 2 & 7 \\
\hline
\end{tabular}

SNAP, Supplemental Nutrition Assistance Program.

version 16.17. Quantitative data were used to produce descriptive statistics (frequencies and percentages) and qualitative data underwent thematic analysis, using both deductive and inductive coding.

\section{Results}

\section{Patient interviews}

Of the thirty patients interviewed, $67 \%$ were female; $73 \%$ were Black; mean age was 40 years; and $53 \%$ had children in their household (Table 1). Sixty percent of interviewees resided in food-insecure households in the past month; $53 \%$ participated in the Supplemental Nutrition Assistance Program (SNAP); and $50 \%$ used other food pantries in addition to the hospital-based pantry. Most interviewees $(73 \%)$ had been using the pantry for at least one year, and $43 \%$ reported visiting the pantry every two weeks (the maximum frequency allowed).

Patients had positive experiences at the pantry, describing the staff as friendly and well-organized (Table 2). Compared with their experiences at other food pantries, patients expressed more trust in the food provided by the hospital pantry, higher satisfaction with the nutritional quality of food, and greater convenience. Patients also indicated that using the hospital-based pantry can be less stigmatizing than using other pantries.

Patients discussed varying experiences with FI. Some reported that the pantry helps alleviate stress related to having enough food. Others described persistent hunger. Patients listed lack of money as a barrier to adhering to medically-prescribed diets and to eating a healthy and varied diet. Many cited the pantry's role in helping them eat healthier. Patients described being exposed to new vegetables at the pantry, and some referred to having voluntarily purchased these vegetables since being introduced at the pantry. Others mentioned leaving unfamiliar vegetables behind or giving them away because they did not know how to prepare them.

While patients were satisfied with the amount of fruits and vegetables supplied at the pantry, some expressed concern about the healthfulness of other foods distributed and questioned whether food was consistently medically tailored. One patient summarized these perceptions:

I don't see too much unhealthy, cause they give out a lot of fresh vegetables. I mean they give out rice and canned goods, but a lot of that stuff somewhat is healthy. Don't get me wrong, I get some of the snack things, but then some of those are like a low-fat food thing... Unless they get a bunch of stuff that was donated and they need to get rid, like the candy or something. They'll give it away.

Some patients had heard of or attended classes at the teaching kitchen, while others were not aware of this resource. When asked about unmet nutrition education needs, patients expressed interest in receiving recipes, diabetes education, and learning how to cook using a microwave.

In concluding the interviews, patients were asked: 'What would have to happen for you not to need the food pantry?' Responses indicated that low income, unemployment or underemployment, cost of housing, and lack of access to federal nutrition assistance programmes were the reasons they continued to need the food pantry. Some said they had not previously considered life without a food pantry ('I never thought about that. I never really thought about for me not to come here').

\section{Provider survey}

Eighty-nine providers completed at least $50 \%$ of the survey, with an overall response rate of $34 \%$ (Table 3). Most were from the Internal Medicine (67\%) and/or Pediatrics (24\%) 
Table 2 Themes and representative quotes from patient interviews

\begin{tabular}{|c|c|}
\hline Theme & Quote \\
\hline \multicolumn{2}{|l|}{ Pantry experience } \\
\hline Overall & $\begin{array}{l}\text { 'I'm happy with their services because they treat us well. Though we are coming for free stuff, } \\
\text { we have some level of dignity. They are treating us well and they talk to you nicely, not } \\
\text { make you feel inferior or something' }\end{array}$ \\
\hline Trust & $\begin{array}{l}\text { 'A hospital is an atmosphere where they're gonna make sure that everything is legit with the } \\
\text { food, is healthy, and l'm pretty sure it's more a nutrition thing with them. And it's clean. } \\
\text { There's a lot of pantries you second guess getting food from them. Because of the } \\
\text { atmosphere. I'm pretty sure they refer you, there's a reason for referrals. And l'm pretty sure } \\
\text { they have their situation, they gotta make sure the food's right' }\end{array}$ \\
\hline Convenience & $\begin{array}{l}\text { 'It's great because I have everything under one roof. All my doctors, all my services, so it's } \\
\text { very convenient for me to go to one place for everything' }\end{array}$ \\
\hline Stigma & $\begin{array}{l}\text { 'I know a food pantry that's at my church. And l've never gone there. Why? Because I don't } \\
\text { want other people to see me. So I think I like this because it's discrete. And it's like it's part } \\
\text { of management of your health' }\end{array}$ \\
\hline \multicolumn{2}{|r|}{ or managemerit or your nealum } \\
\hline Alleviated & $\begin{array}{l}\text { 'Knowing that you can come twice a month has really gotten me through those hard } \\
\text { times... when you just see yourself right on 'E' [referring to 'empty'] or close to 'E,' you } \\
\text { come in here twice a month and it lifts you right back up to where you need to be' }\end{array}$ \\
\hline Persistent & $\begin{array}{l}\text { 'I eat the least so I can spare food for the rest of my family. I eat very little and I take lots of } \\
\text { water to supplement' }\end{array}$ \\
\hline \multicolumn{2}{|r|}{ vater to suppientili } \\
\hline Nutritional quality & $\begin{array}{l}\text { 'If I didn't do the food pantry, I still wouldn't have the amount I needed as part of nutrition, } \\
\text { cause I'm on that budget. Opposed to with the pantry I can get some more fruits here and } \\
\text { there, and I'm okay' }\end{array}$ \\
\hline Variety & $\begin{array}{l}\text { 'I love to eat healthy but circumstances doesn't allow it. I love fruits and vegetables but I really } \\
\text { don't have them on a daily basis' }\end{array}$ \\
\hline Adherence to medical diet & $\begin{array}{l}\text { 'I can't even afford to buy the protein drink that I'm supposed to have since I had the gastric } \\
\text { bypass' }\end{array}$ \\
\hline Introduced to new vegetables & $\begin{array}{l}\text { 'Zucchini. I hadn't eaten that before but when I brought it home my friend knew how to cook it. } \\
\text { And it was good, the first time I ate that I was like wow' }\end{array}$ \\
\hline Purchased at store & $\begin{array}{l}\text { 'Before I wouldn't dare buy an eggplant, now I break my neck! Yep, and l've been eating all } \\
\text { kinds of leaves. It's good, I love it' }\end{array}$ \\
\hline Left on cart & 'They said how to cook it but I still ain't know how to do that and I said nope, I ain't doin' it' \\
\hline \multicolumn{2}{|l|}{ Pantry food } \\
\hline \multirow[t]{2}{*}{ Healthy } & $\begin{array}{l}\text { 'What I like about you guys is you give out more fruits and vegetables than all the other } \\
\text { pantries. And I like that' }\end{array}$ \\
\hline & $\begin{array}{l}\text { 'I've learned a lot from the food pantry ... l've learned that everything they give is healthy } \ldots \\
\text { there's no sugar, there's no salt' }\end{array}$ \\
\hline \multirow[t]{2}{*}{ Unhealthy } & $\begin{array}{l}\text { 'The concern is with all the starch stuff. Spaghetti, you get the spaghetti, you get macaroni, } \\
\text { and you get potatoes a lot. And l'm like okay, but I don't eat it all the time' }\end{array}$ \\
\hline & $\begin{array}{l}\text { 'At the beginning we received sweet food, salty food. But I had to ask for a letter for them, } \\
\text { about this item. No salted food, no sweet food' }\end{array}$ \\
\hline Medical tailoring & 'Sometimes I don't get things that I can eat, cause I'm a diabetic' \\
\hline \multicolumn{2}{|l|}{ Nutrition education } \\
\hline \multicolumn{2}{|l|}{ Teaching Kitchen } \\
\hline Aware & $\begin{array}{l}\text { 'I try to eat healthy so I go to the kitchen upstairs sometimes. I can't make it every time they } \\
\text { have cooking classes for the diabetic people because of the days that they have it one, } \\
\text { because I have a lot of hospital appointments because I have health problems. So I have } \\
\text { menus that I've gotten from the kitchen and I try to utilize some of the recipes' }\end{array}$ \\
\hline Not aware & $\begin{array}{l}\text { 'I didn't know they had that. I never heard of that here. If I could spare the time l'd come and } \\
\text { see what they're talking about' }\end{array}$ \\
\hline Unmet nutrition education needs & $\begin{array}{l}\text { 'They probably can give out more recipes for healthy stuff. I would use them' } \\
\text { '[l'd like to learn] more probably about diabetes and how that really affects you' } \\
\text { 'We have microwaves in our apartment, so if they could show me how to cook in a microwave } \\
\text { I would like that' }\end{array}$ \\
\hline
\end{tabular}


Table 3 Characteristics of providers, by position

\begin{tabular}{|c|c|c|c|c|c|c|c|c|}
\hline \multirow[b]{3}{*}{ Characteristic } & \multicolumn{8}{|c|}{ Position } \\
\hline & \multicolumn{2}{|c|}{ Total } & \multicolumn{2}{|c|}{ Attending } & \multicolumn{2}{|c|}{ Resident } & \multirow[b]{2}{*}{ Other* } & \\
\hline & $n$ & $\%$ & $n$ & $\%$ & $n$ & $\%$ & & \\
\hline Total & 89 & & 47 & & 25 & & 17 & \\
\hline Age (mean, SD) & 40 & 13 & 47 & 12 & 29 & 2 & 41 & 15 \\
\hline \multicolumn{9}{|l|}{ Sex } \\
\hline Female & 62 & 70 & 30 & 64 & 16 & 64 & 16 & 94 \\
\hline \multicolumn{9}{|l|}{ Department } \\
\hline IM & 58 & 65 & 25 & 53 & 25 & 100 & 8 & 47 \\
\hline Pediatrics & 19 & 21 & 15 & 32 & & & 4 & 24 \\
\hline Both IM and Pediatrics & 2 & 2 & 2 & 4 & & & & \\
\hline \multicolumn{9}{|l|}{ Other } \\
\hline Psychiatry & 6 & 7 & 1 & 2 & & & 5 & 29 \\
\hline Family Medicine & 1 & 1 & 1 & 2 & & & & \\
\hline \multirow{2}{*}{\multicolumn{9}{|c|}{ Years in practice }} \\
\hline & & & & & & & & \\
\hline $0-5$ & 33 & 37 & 3 & 6 & 25 & 100 & 5 & 29 \\
\hline $6-10$ & 23 & 26 & 16 & 34 & & & 7 & 41 \\
\hline $11-15$ & 7 & 8 & 7 & 15 & & & & \\
\hline$>15$ & 26 & 33 & 21 & 45 & & & 5 & 29 \\
\hline
\end{tabular}

IM, Internal Medicine.

*Includes Nurse Practitioners, Social Workers, Patient Navigator, and one provider with unspecified position.

Table 4 Provider perspectives on food insecurity, by position

\begin{tabular}{|c|c|c|c|c|c|c|c|c|c|c|}
\hline & \multicolumn{10}{|c|}{ Position } \\
\hline & \multicolumn{2}{|c|}{ Total } & \multicolumn{2}{|c|}{ Attending } & \multicolumn{2}{|c|}{ Resident } & \multicolumn{2}{|c|}{ PN } & \multirow{2}{*}{\multicolumn{2}{|c|}{ Other* }} \\
\hline & $n$ & $\%$ & $n$ & $\%$ & $n$ & $\%$ & $n$ & $\%$ & & \\
\hline \multicolumn{11}{|c|}{ Do you ever discuss FI with your patients? } \\
\hline Yes, regularly & 46 & 52 & 28 & 60 & 5 & 20 & 1 & 100 & 13 & 76 \\
\hline Yes, occasionally & 40 & 45 & 17 & 36 & 19 & 76 & & & 4 & 24 \\
\hline No, never & 3 & 3 & 2 & 4 & 1 & 4 & & & & \\
\hline \multicolumn{11}{|c|}{$\begin{array}{l}\text { Do you think that providers should speak } \\
\text { with their patients about FI? }\end{array}$} \\
\hline Yes & 88 & 99 & 47 & 100 & 25 & 100 & 1 & 100 & 16 & 95 \\
\hline No & 1 & 1 & & & & & & & 1 & 6 \\
\hline \multicolumn{11}{|c|}{ What type of training, if any, have you received on FI? } \\
\hline Attended a lecture & 46 & 52 & 20 & 42 & 19 & 76 & & & 7 & 41 \\
\hline Med school coursework & 20 & 22 & 9 & 19 & 10 & 40 & & & 1 & 6 \\
\hline I have personally experienced FI & 10 & 11 & 6 & 13 & 2 & 8 & & & 2 & 12 \\
\hline Other & 29 & 32 & 17 & 36 & 2 & 8 & 1 & 100 & 8 & 47 \\
\hline None & 9 & 10 & 8 & 17 & 1 & 4 & & & & \\
\hline \multicolumn{11}{|c|}{$\begin{array}{l}\text { Do you feel you have received sufficient training on } \\
\text { discussing FI with patients? }\end{array}$} \\
\hline Yes & 47 & 53 & 20 & 42 & 17 & 68 & & & 10 & 59 \\
\hline No & 42 & 47 & 27 & 57 & 8 & 32 & 1 & 100 & 7 & 41 \\
\hline
\end{tabular}

FI, food insecurity.

*Includes Nurse Practitioners, Social Workers, Patient Navigator, and one provider with unspecified position.

meds if all money spent on food'); insight they can gain into patients' lives ('It is helpful for providers to ask this question to understand where patients are coming from and to make sure recommendations they are making are realistic'); and providers' ability to refer patients to helpful resources ('We have resources at our institution to help').

Fifty-eight percent of providers reported having received some formal training on FI in the form of a lecture or training. However, only $53 \%$ of providers felt they had received sufficient training. Providers practising for 10 or more years were less likely to have received formal training on FI (35\%), and less likely to feel they had sufficient training on discussing FI with patients ( $45 \%$ ), compared with providers practising for under 10 years $(78 \%$ and $59 \%$, respectively). Suggestions for additional training on discussing FI with patients centred on lecturebased educational opportunities, such as Grand Rounds, and having access to information on local 
Table 5 Provider perspectives on the pantry, by position*

\begin{tabular}{|c|c|c|c|c|c|c|c|c|}
\hline & \multicolumn{8}{|c|}{ Position } \\
\hline & \multicolumn{2}{|c|}{ Total } & \multicolumn{2}{|c|}{ Attending } & \multicolumn{2}{|c|}{ Resident } & \multicolumn{2}{|c|}{ Other $^{\dagger}$} \\
\hline & $n$ & $\%$ & $n$ & $\%$ & $n$ & $\%$ & $n$ & $\%$ \\
\hline \multicolumn{9}{|l|}{ Are you familiar with the Pantry? } \\
\hline Yes & 84 & 98 & 46 & 98 & 24 & 100 & 14 & 93 \\
\hline No & 2 & 2 & 1 & 2 & & & 15 & 7 \\
\hline $\begin{array}{l}\text { In the past } 10 \mathrm{~d} \text {, approximately what } \\
\text { percentage of your patients who } \\
\text { were identified as food insecure } \\
\text { did you refer to the pantry?†‡ }\end{array}$ & 80 & & 45 & & 20 & & & \\
\hline $90-100 \%$ & 24 & 30 & 16 & 36 & 3 & 15 & 5 & 33 \\
\hline $50-89 \%$ & 24 & 30 & 11 & 24 & 6 & 30 & 7 & 47 \\
\hline$<50 \%$ & 20 & 25 & 13 & 29 & 5 & 25 & 2 & 13 \\
\hline $\begin{array}{l}\text { None of my patients were identified } \\
\text { as food insecure }\end{array}$ & 12 & 15 & 5 & 11 & 6 & 30 & 1 & 7 \\
\hline \multicolumn{9}{|l|}{$\begin{array}{l}\text { Which of the following prevented you } \\
\text { from referring all patients identified } \\
\text { as food insecure to the pantry? } \\
\text { (more than one apply) }\end{array}$} \\
\hline Time constraints & 30 & 35 & 13 & 28 & 10 & 42 & 7 & 47 \\
\hline $\begin{array}{l}\text { Patient lives too far away or } \\
\text { uninterested }\end{array}$ & 27 & 31 & 14 & 30 & 9 & 38 & 4 & 27 \\
\hline Forgot & 22 & 26 & 13 & 28 & 8 & 33 & 1 & 7 \\
\hline Referral process & 19 & 22 & 10 & 21 & 7 & 29 & 2 & 13 \\
\hline No constraints & 10 & 12 & 8 & 17 & & & 2 & 13 \\
\hline Fear of offending the patient & 3 & 3 & & & 2 & 8 & 1 & 7 \\
\hline Other & 14 & 16 & 6 & 13 & 5 & 21 & 3 & 20 \\
\hline \multicolumn{9}{|l|}{$\begin{array}{l}\text { Do you think using the Pantry improves } \\
\text { the health of your patients? }\end{array}$} \\
\hline Yes & 83 & 97 & 44 & 94 & 24 & 100 & 15 & 100 \\
\hline No & 3 & 3 & 3 & 6 & & & & \\
\hline
\end{tabular}

${ }^{*} n 86$ for this table due to non-response by three providers.

†Includes Nurse Practitioners and Social Workers.

$\ddagger n$ for this item excludes providers who noted that they practice at community health centres, inpatient medicine, or do not have any patients (and therefore would not be expected to refer patients to the pantry).

resources. Specific content requests included: 'How to start a conversation about food insecurity'; 'How to address it effectively in a short amount of time'; and 'Tips to address [FI] without shaming.'

Ninety-seven percent of providers believed the pantry improves the health of their patients (Table 5). Reasons included access to food ('It is one of the only ways they can have access to food that is accessible, safe and consistent'), access to healthy food ('Provides healthy food catered to illness'), improved well-being ('It reduces anxiety about searching for food ... It is one less burden for them to wrestle with in regards to their overall survival'), and improved connection to the hospital ('Gives them a sense of belonging, connection to [hospital]').

Thirty percent of providers referred $90-100 \%$ of their patients identified as food insecure to the pantry, while another $30 \%$ of providers referred $50-89 \%$ of patients, $25 \%$ of providers referred less than $50 \%$ of patients, and $15 \%$ did not identify any patients as food insecure. 'Time constraints' was the most common barrier to referral (35\% of providers), followed by 'Patient lives too far away or is uninterested in using the pantry' (31\%). Twenty-six percent of providers reported they sometimes 'Forgot' to refer, and $22 \%$ indicated issues with the referral process, such as not understanding how to make a referral or not seeing results of patients' SDH screeners until after patients left the office. Three providers said 'Fear of offending the patient' prevented referral. Another barrier was lack of ready-to-eat foods for homeless patients without access to kitchens.

\section{Discussion}

\section{The role of a bospital-based food pantry}

Food insecurity adversely affects the physical and mental health of millions of people in the US, and healthcare institutions can play a role in addressing this public health crisis. Hospital-based food pantries can provide access to highquality food in a convenient, trustworthy, low-stigma environment. The role of integrating medical and social services in increasing efficiency and user satisfaction has been 
acknowledged for decades. In 1999, Leutz described how integration would make the "confusing systems of health and human services ... more "user-friendly" ... by creating single access points for multiple services ${ }^{,(20)}$. Nearly 20 years later, this appears to hold true as patients extol the convenience and simplicity of the hospital-based food pantry.

Interviews revealed that patients may have greater confidence in food provided at hospital-based food pantries due to perceptions of greater liability and higher standards for food safety. Past research reveals major concerns among food pantry clients include food safety, as they often receive expired and spoiled food ${ }^{(21,22)}$ and perceived stigma of using food assistance resources, which prevents some people from accessing necessary services ${ }^{(23,24)}$. Our results suggest that hospital-based food pantries may eliminate this barrier for some patients by providing a more discreet setting and by tying food assistance to healthcare.

Medically-tailored, hospital-based food pantries that aim to simultaneously address food insecurity and chronic disease are well-positioned to lead in nutritional quality of food assistance. The current study shows that the pantry is already helping some patients improve their diets by increasing access to fruits and vegetables and introducing patients to new, healthy foods. This pantry fills a critical gap in services, as studies show food pantry clients prefer receiving healthy foods such as fruits and vegetables compared with snacks, soda, and candy ${ }^{(21,25)}$, yet most pantries do not provide food that supports a healthy, balanced diet ${ }^{(26)}$.

We encourage hospital-based pantries to take advantage of additional opportunities to promote health by establishing policies that prevent distribution of unhealthy items to any patients, regardless of present diagnoses. Such policies could include nutrition commitments and guidelines for foods that pantries will and will not accept as donations ${ }^{(17)}$. All individuals should have access to healthy food that does not make them sick, and receiving unhealthy food at pantries can contribute to poor health outcomes and exacerbate income-based health disparities. Furthermore, since patients must be referred by their healthcare providers, they may believe all food received at the pantry has their provider's endorsement. Receiving unhealthy food at a hospital-based food pantry sends contradictory messages to patients about how to eat healthy and manage their disease.

Hospitals can also support patients in adopting healthy diets by offering nutrition education programming. This study revealed that there may have been a missed opportunity, wherein some patients using the pantry were not aware of the hospital's teaching kitchen. Hospital-based food pantries should partner with free nutrition education programmes and promote these programmes regularly and consistently to all patients.

\section{Lessons for healthcare organizations}

As healthcare delivery systems across the country transition to value-based, comprehensive care, there is an increasing expectation that SDH be addressed in the clinical setting ${ }^{(27)}$. Results of the current study align with those from a 2017 survey, which found that physicians believe SDH affect the health of their patients ${ }^{(28)}$. However, although the 2017 survey found that a majority of physicians do not consider it their responsibility to help patients get sufficient food, the current study found that $99 \%$ of providers at one hospital see these conversations as part of their role. This could suggest that physicians at hospitals with onsite resources such as a food pantry are more likely to feel responsible for addressing their patients' FI.

The current study found that even providers who believe they should help address SDH face barriers, such as insufficient training. Providers in all positions and at all stages of their careers expressed interest in receiving additional training. Per the recommendations of providers in this study, hospitals implementing FI screening are encouraged to offer educational sessions, and medical schools are also encouraged to integrate training on FI and nutrition into their curricula ${ }^{(29,30)}$.

Finally, it is of the utmost importance that hospitals implementing FI screening address any barriers to resource referral as screening without an available treatment can be considered unethical ${ }^{(31)}$. To avoid unintended harm, hospitals must work to ensure that all patients that screen positive for FI and request help connecting to food resources are referred to a pantry or are connected with other community food resources. This can be achieved through implementation of quality improvement measures that ensure the timely flow of information in the clinic, and systems for patient outreach and follow-up when referrals are not made at time of visit. Additionally, since time constraints were the most common barrier preventing providers from completing food pantry referrals, healthcare systems should consider additional or extended visits for these patients and fully utilize existing coding opportunities. For example, coding for a diagnosis of 'Lack of Adequate Food and Safe Drinking Water' increases the level of complexity of a visit and may enable providers to spend more time with patients that receive this diagnosis. Coding for FI can also provide hospitals with data that helps them understand the risks faced by their patient populations and to develop programmes to tackle these risks ${ }^{(32,33)}$.

\section{Limitations}

The current study had several limitations: (i) we used a nonrandomized, convenience sample of patients; (ii) although the questionnaires were developed by a team of experts, they were not previously validated; (iii) interviews were conducted in English only; and (iv) the provider sample may include selection bias, as those interested in FI may have been more likely to respond. The provider response rate may also reflect bias, as the online survey may have been forwarded via email to providers not included in the original sample. 


\section{Conclusion}

Our findings suggest hospital-based food pantries may have several advantages. To optimize their impact, these pantries should develop nutritional guidelines for food donations and connect patients with nutrition education resources. Hospitals, particularly those with onsite food pantries, must work to eliminate barriers to FI screening and pantry referral. Since FI is typically a symptom of a larger problem, hospital-based food pantries may also act as venues to connect patients with other resources and services - such as SNAP, housing, and employment and training programmes - that can help address the root causes of FI. Future research should examine outcomes related to health, FI, and healthcare utilization and costs for patients using hospital-based food pantries.

\section{Acknowledgements}

The authors gratefully acknowledge Latchman Hiralall, DTR, Rachel Zack, Sc.D., and Stephanie Ettinger de Cuba, MPH, for their substantive contributions to this study. Financial support: This work was partially supported by the Morton A. Madoff Public Health Fellowship from Tufts University School of Medicine (E.G.). The sponsor had no role in the design, analysis, or writing of this article. This research received no other specific grant from any funding agency, commercial or non-profit sectors. Conflict of interest: None. Authorship: E.G. designed the survey tools; performed data collection and analysis; and drafted the manuscript. A.P. provided oversight for data analysis and significant edits to the manuscript. J.J. performed qualitative data analysis validation; provided oversight for data collection and analysis; and provided significant edits to the manuscript. T.J. provided oversight for data collection and significant edits to the manuscript. Ethics of human subject participation: This study was conducted according to the guidelines laid down in the Declaration of Helsinki and all procedures involving human subjects/patients were approved by the Tufts Health Sciences Campus Institutional Review Board (IRB\#: 12922). Written or verbal informed consent was obtained from all subjects/patients. Verbal consent was witnessed and formally recorded.

\section{Supplementary material}

To view supplementary material for this article, please visit https://doi.org/10.1017/S1368980019002040

\section{References}

1. Crowe J, Lacy C \& Columbus Y (2018) Barriers to food security and community stress in an urban food desert. Urban Sci 2, 46.
2. Shannon J (2018) From food deserts to supermarket redlining: making sense of food access in Atlanta. Atlanta Studies 2019. https://www.atlantastudies.org/2018/08/14/ jerry-shannon-from-food-deserts-to-supermarket-redliningmaking-sense-of-food-access-in-atlanta/.

3. Coleman-Jensen A, Rabbitt MP, Gregory CA et al. (2018) Household Food Security in the United States in 2017. https://www.ers.usda.gov/webdocs/publications/90023/ err256_summary.pdf?v=0 (accessed December 2018).

4. USDAERS (2018) Food Security in the U.S.: Measurement. https://www.ers.usda.gov/topics/food-nutrition-assistance/ food-security-in-the-us/measurement.aspx (accessed 8 October 2018).

5. Gundersen C \& Ziliak JP (2015) Food insecurity and health outcomes. Health Aff (Millwood) 34, 1830-1839.

6. Ding M, Keiley MK, Garza KB et al. (2015) Food insecurity is associated with poor sleep outcomes among US adults. J Nutr 145, 615-621.

7. Seligman HK, Laraia BA \& Kushel MB (2010) Food insecurity is associated with chronic disease among low-income NHANES participants. J Nutr 140, 304-310.

8. Whitaker RC, Phillips SM \& Orzol SM (2006) Food insecurity and the risks of depression and anxiety in mothers and behavior problems in their preschool-aged children. Pediatrics 118, e859-e868.

9. Rhone A, Ver Ploeg M, Dicken C et al. (2017) Low-income and low-supermarket-access census tracts, 2010-2015. USDAERS.

10. Colon-Ramos U, Finney Rutten LJ, Moser RP et al. (2015) The association between fruit and vegetable intake, knowledge of the recommendations, and health information seeking within adults in the U.S. mainland and in Puerto Rico. J Health Commun 20, 105-111.

11. Parmenter K, Waller J \& Wardle J (2000) Demographic variation in nutrition knowledge in England. Health Educ Res 15, 163-174.

12. Dallman MF, Pcoraro N, Akana SF et al. (2003) Chronic stress and obesity: a new view of 'comfort food'. PNAS 100, 11696-11701.

13. Seligman HK, Jacobs EA, Lopez A et al. (2012) Food insecurity and glycemic control among low-income patients with Type 2 diabetes. Diabetes Care 35, 233-238.

14. (2014) Healthy Food Donation List. Feeding America.

15. Rivera C, Alford S, Isham M et al. (2016) The Power of Nudges: Making the Healthy Choice the Easy Choice in Food Pantries. Chicago, IL: Feeding America.

16. Washington State University (2018) Healthy Food Pantry Assessment Toolkit. https://extension.wsu.edu/pierce/ nutrition/healthy-food-pantry-assessment-toolkit/ (accessed 8 October 2018).

17. Handforth B, Hennink M \& Schwartz MB (2013) A qualitative study of nutrition-based initiatives at selected food banks in the feeding America network. J Acad Nutr Diet 113, 411-415.

18. AAP Council On Community Pediatrics CON (2015) Promoting food security for all children. Pediatrics 136, e1431-e1438.

19. Hager ER, Quigg AM, Black MM et al. (2010) Development and validity of a 2 -item screen to identify families at risk for food insecurity. Pediatrics 126, e26-e32.

20. Leutz WN (1999) Five laws for integrating medical and social services: lessons from the United States and the United Kingdom. Milbank Q 77, 77-110.

21. Verpy H, Smith C \& Reicks M (2003) Attitudes and behaviors of food donors and perceived needs and wants of food shelf clients. J Nutr Educ Behav 35, 6-15.

22. Ginsburg ZA, Bryan AD, Rubinstein EB et al. (2018) Unreliable and difficult-to-access food for those in need: a qualitative and quantitative study of urban food pantries. J Community Health 44, 16-31.

23. Martin KS, Cook JT, Rogers BL et al. (2003) Public versus private food assistance: barriers to participation differ by age and ethnicity. J Nutr Educ Behav 35, 249-254. 
24. El Zein A, Mathews AE, House L et al. (2018) Why are hungry college students not seeking help? Predictors of and barriers to using an on-campus food pantry. Nutrients 10, 1163.

25. Campbell E, Hudson H, Webb K et al. (2011) Food preferences of users of the emergency food system. J Hunger Environ Nutr 6, 179-187.

26. Simmet A, Depa J, Tinnemann P et al. (2017) The nutritional quality of food provided from food pantries: a systematic review of existing literature. J Acad Nutr Diet 117, 577-588.

27. Bart C \& Tabone J (1998) Mission statement rationales and organizational alignment in the not-for-profit health care sector. Health Care Manage Rev 23, 54-69.

28. Winfield L, DeSalvo K \& Muhlstein D (2018) Social Determinants Matter, But Who Is Responsible?: 2017 Physician Survey on Social Determinants of Health. Salt Lake City, Utah: Leavitt Partners.
29. Webb L (2011) Standing in the patient's shoes: medical students take the SNAP Challenge. Med Educ $\mathbf{4 5}$, $1135-1136$.

30. Aspry KE, Van Horn L, Carson JAS et al. (2018) Medical nutrition education, training, and competencies to advance guideline-based diet counseling by physicians: a science advisory from the American heart association. Circulation 137, e821-e841.

31. Garg A, Boynton-Jarrett R \& Dworkin PH (2016) Avoiding the unintended consequences of screening for social determinants of health. JAMA 316, 813-814.

32. Dugdale D, Epstein R \& Pantilat S (1999) Time and the patient-physician relationship. JGIM 14, S34-S40.

33. DeSilvey S, Ashbrook A, Sheward R et al. (2018) An Overview of Food Insecurity Coding in Health Care Settings: Existing and Emerging Opportunities. Boston, MA: Hunger Vital Sign $^{\mathrm{TM}}$ National Community of Practice. 